\title{
Effect of thalidomide in combination with gemcitabine on human pancreatic carcinoma SW-1990 cell lines in vitro and in vivo
}

\author{
ZHENGUO QIAO $^{1}$, JIGANG YUAN ${ }^{2}$, JIAQING SHEN $^{3}$, CHAO WANG $^{3}$, \\ ZHILONG $\mathrm{HE}^{3}$, YIJIA $\mathrm{HU}^{3}$, MUXING ZHANG ${ }^{3}$ and CHUNFANG XU ${ }^{3}$ \\ ${ }^{1}$ Department of Gastroenterology, Affiliated Wujiang Hospital of Nantong University, Suzhou, Jiangsu 215200; \\ ${ }^{2}$ Department of Gastroenterology, Nanjing Drum Tower Hospital, Nanjing, Jiangsu 210008; \\ ${ }^{3}$ Department of Gastroenterology, The First Affiliated Hospital of Soochow University, Suzhou, Jiangsu 215006, P.R. China
}

Received June 5, 2014; Accepted March 2, 2015

DOI: $10.3892 / 01.2015 .3064$

\begin{abstract}
Pancreatic cancer is one of the most frequently occurring malignancies worldwide and it is the fourth most common cause of cancer-associated mortality in Western countries. Thalidomide (THD) plays an important role in tumor therapy, as it is able to promote early stage apoptosis and inhibit the process of angiogenesis. The present study evaluated the ability of the combination of THD and gemcitabine (GEM) to inhibit the growth of the pancreatic cancer SW-1990 cell line in vitro and in vivo. Early apoptosis in the SW-1990 cells was detected by the Annexin V/propidium iodide double staining method, the level of B-cell lymphoma 2 (Bcl-2) and $\mathrm{Bcl}-2$-associated $\mathrm{X}$ protein (Bax) were detected by reverse transcription-polymerase chain reaction (RT-PCR) and western blot analysis. In addition, the expression of vascular endothelial growth factor in transplanted tumor tissue was measured by RT-PCR, immunohistochemistry and western blot analysis. Cluster of differentiation 34 positivity was considered to indicate the microvessel density. Subsequent to treatment with THD and GEM alone or in combination, it was found that the expression of Bax was upregulated, while the expression of Bcl-2 was downregulated, and the growth of SW-1990 cells and transplanted tumors in nude mice was evidently inhibited. The administration of THD in combination with GEM may demonstrate a potent antitumor effect that increases with increasing dose. The mechanism behind the antitumor effect may be associated with the inhibition of tumor angiogenesis and induction of the apoptosis pathway.
\end{abstract}

Correspondence to: Professor Chunfang $\mathrm{Xu}$, Department of Gastroenterology, The First Affiliated Hospital of Soochow University, 188 Shizi, Suzhou, Jiangsu 215006, P.R. China E-mail: xcf601@126.com

Key words: thalidomide, gemcitabine, pancreatic cancer, apoptosis, angiogenesis

\section{Introduction}

Pancreatic cancer is one of the most common malignancies and the fourth leading cause of cancer-associated mortality in the USA (1). During previous decades, the diagnosis and treatment of pancreatic adenocarcinoma has been notably improved. However, pancreatic cancer continues to possess the poorest prognosis of any human cancer. Overall, $>85 \%$ of patients have lost the opportunity for surgical intervention at the time of diagnosis, and therefore, chemotherapy is important in the treatment of advanced pancreatic cancer (2). Gemcitabine (GEM) is the conventional chemotherapeutic drug used in the treatment of pancreatic cancer. Unfortunately, the therapeutic effect of GEM is poor $(3,4)$. Therefore, a novel treatment strategy that is able to enhance the anti-tumor effect of GEM is urgently required.

$\alpha-\mathrm{N}$-phthalimidoglutarimide, also known as thalidomide (THD), was introduced in the 1950s as an antiemetic and sedative in Europe. However, the drug was rapidly banned due to teratogenic effects (5). In 1994, THD was found to be an antiangiogenic agent (6). Subsequently, it was revealed in 1999 that THD can be used in the treatment of multiple myeloma (7). In the following years, a large number of studies revealed that THD exerted an antitumor effect in several types of cancer, including prostate, colorectal, non-small-cell lung and breast cancer, and renal cell carcinoma (8-12). The invasion and metastasis of tumors depends on the process of angiogenesis, and THD may be able to inhibit the growth of tumor tissue by preventing the development of the necessary blood vessels. In addition, THD may promote early-stage apoptosis and inhibit the proliferation of carcinoma cells $(13,14)$. However, the antitumor mechanism of THD has yet to be elucidated.

B-cell lymphoma 2 (Bcl-2), is an anti-apoptotic protein, which protects against cell death; by contrast, Bcl-2-associated $\mathrm{X}$ protein (Bax) exhibits the opposite effect, promoting cell death. Vascular endothelial growth factor (VEGF) has also been demonstrated to be a significant indicator of tumor angiogenesis.

The aim of the present study was to investigate the effect and mechanism of THD in combination with GEM on the human pancreatic carcinoma SW-1990 cell line in vitro and in vivo by monitoring levels of Bcl-2, Bax and VEGF. 


\section{Materials and methods}

Cell lines and cell culture. The human pancreatic carcinoma SW-1990 cell line was provided by the Department of Gastroenterology at the Changhai Hospital of The Second Military Medical University (Shanghai, China). The cells were grown in $75 \mathrm{~cm}^{2}$ cell culture flasks and maintained in RPMI-1640 medium (Gibco Life Technologies, Carlsbad, CA, USA) supplemented with $10 \%$ heat-inactivated fetal bovine serum (Gibco Life Technologies), 100 units/ml penicillin and $100 \mu \mathrm{g} / \mathrm{ml}$ streptomycin at $37^{\circ} \mathrm{C}$ in a humidified atmosphere of $95 \%$ air and $5 \% \mathrm{CO}_{2}$.

Cell counting kit (CCK)- 8 assay. The SW-1990 cells were trypsinized with $0.05 \%$ trypsin when $80 \%$ confluency was achieved. The cells were then plated into 96-well plates, with $100 \mu \mathrm{l}$ medium per well, and cultured overnight in RPMI-1640 medium. THD $(0-200 \mu \mathrm{g} / \mathrm{ml}$; Calbiochem, San Diego, CA, USA) was added to the cells, with six replicates being performed for each concentration. After 24,48 or $72 \mathrm{~h}$ incubation, the cell viability was determined using a CCK-8 assay (Peptide Institute, Inc., Osaka, Osaka, Japan), and the survival and inhibition rates of the cells were calculated. In the combined treatment condition, $50 \mu \mathrm{g} / \mathrm{ml}$ THD and $20 \mu \mathrm{mol} / 1$ GEM were tested alone or in combination for their ability to inhibit the proliferation of the SW-1990 cell line using the aforementioned method.

Annexin V/propidium iodide (PI) assay. The SW-1990 cells were seeded into six-well plates, and treated with normal saline and THD at various concentrations $(0,25,50,100,150$, and $200 \mu \mathrm{g} / \mathrm{ml}$ ). The cells were collected $48 \mathrm{~h}$ later and washed twice using cold phosphate-buffered saline (PBS). The cells were then trypsinized and stained using an Annexin V/PI double staining solution (Sigma-Aldrich, St. Louis, MO, USA) at room temperature. After $15 \mathrm{~min}$, the Annexin V/PI stained cells were analyzed by flow cytometry using the ModFitLT software (Verity Software House, Topsham, ME, USA), and the percentage of apoptotic and necrotic cells was calculated. In the combined treatment investigation, the cells were treated with $50 \mu \mathrm{g} / \mathrm{ml}$ THD, $20 \mu \mathrm{mol} / 1$ GEM or $50 \mu \mathrm{g} / \mathrm{ml}$ THD and $20 \mu \mathrm{mol} / \mathrm{l} \mathrm{GEM}$ in combination. The analysis of cell death was performed by flow cytometry, as previously described (15).

Animals. Female athymic Balb/c nu/nu mice aged 4-6 weeks and weighing 15-16 g were obtained from Shanghai Laboratory Animal Center (Chinese Academy of Sciences, Shanghai, China). The mice were housed in a laminar airflow cabinet under specific pathogen-free conditions and were allowed free access to sterilized water and standard pellet food. The protocol for the in vivo study was in accordance with the guidelines of animal care and was approved by the Soochow University Animal Experiments Committee (Suzhou, Jiangsu, China) (16).

Nude mouse xenograft assay. For the nude mice xenograft assay, the SW-1990 cells were trypsinized and resuspended in serum-free RPMI-1640 at a concentration of $1 \times 10^{7}$ cells $/ \mathrm{ml}$. The cell suspension was then subcutaneously injected into the right anterior armpit of nude mice to generate a primary transplanted tumor. The mice were divided into four groups:
Normal saline (NS)-treated control group; melatonin-treated group; GEM-treated group; and the combined treatment group. There were five mice per group. When the size of the tumor xenograft reached $\sim 5 \mathrm{~mm}$ in diameter, the mice were administered with $200 \mathrm{mg} / \mathrm{kg}$ THD, $50 \mathrm{mg} / \mathrm{kg}$ gemcitabine or the combined treatment, comprising $200 \mathrm{mg} / \mathrm{kg}$ THD and $50 \mathrm{mg} / \mathrm{kg}$ GEM, through injections provided every other day. Four weeks later, the nude mice were sacrificed and the tumors were measured and weighed. The tumor volume $\left(\mathrm{cm}^{3}\right)$ was calculated as follows: $4 \pi / 3 \times(\text { width } / 2)^{2} \times($ length $/ 2)$

Semi-quantitative RT-PCR assay. Total RNA were extracted from the SW-1990 cells and tumor tissues using TRIzol reagent (Invitrogen, Carlsbad, CA, USA) and quantitated by absorbance analysis performed at $260 \mathrm{~nm}$, according to the manufacturer's instructions. The first-strand cDNA was synthesized in $20 \mu 1$ reaction reagent with $2,000 \mathrm{ng}$ total RNA, using the Omniscript RT kit (Qiagen, Hilden, Germany). The PCR reactions were performed over 45 cycles. Each cycle was performed using the following cycling conditions: Denaturation for $40 \mathrm{sec}$ at $95^{\circ} \mathrm{C}$; annealing for $40 \mathrm{sec}$ at $59^{\circ} \mathrm{C}$; and polymerization for $38 \mathrm{sec}$ at $72^{\circ} \mathrm{C}$. The primers used for the detection of Bcl-2, Bax and VEGF mRNA were as follows: Bcl-2 forward, 5'-CAGCTGCACCTGACGCCCTT-3' and reverse, 5'-GCCTCCGTTATCCTG GATCC-3'; Bax forward, 5'-GCGTCCACCAAGAAGCTGA-3' and reverse, 5'-ACCACCCTGGTCTTGGATCC-3'; VEGF forward, 5'-GGACAGACAGACAGACACCG-3' and reverse, 5'-GCACCCAAGACAGCAGAAAG-3'; and $\beta$-actin forward, 5'-AGCGGGAAATCGTGCGTG-3' and reverse, 5'-CAGGGT ACATGGTGGTGCC-3'.

Western blot assay. The sample proteins were separated on 8-12\% SDS-PAGE and then electroblotted onto nitrocellulose membranes (GenScript USA Inc., Piscataway, NJ, USA). The membranes were blocked with 0.1\% Tween-20 (Wuhan Boster Biological Technology, Ltd., Wuhan, China) in PBS (PBST) containing 5\% fresh milk at room temperature for $60 \mathrm{~min}$. Firstly, the membranes were incubated at $4^{\circ} \mathrm{C}$ overnight with the primary mouse monoclonal antibodies against VEGF, Bcl-2 and Bax (catalog nos. sc-152, sc-56018 and sc-7480, respectively; Santa Cruz Biotechnology, Inc., Dallas, TX, USA). The membranes were then washed with PBST three times and incubated with the appropriate horseradish peroxidase-conjugated secondary antibody at room temperature for 45 min. Finally, the membranes were washed with PBST three times and visualized using an enhanced chemiluminescence detection system (Beyotime, Jiangsu, China).

Immunohistochemistry assay. The tumor tissues were fixed in formalin and embedded in paraffin prior to being sectioned into $4-\mu \mathrm{m}$ thick slices for immunohistochemical staining. Subsequent to deparaffinization, the sections were incubated with the antibodies against VEGF, Bcl-2 and Bax (Santa Cruz Biotechnology, Inc.) at $4^{\circ} \mathrm{C}$ overnight. The primary antibody was then removed and the slices were washed with PBST three times. Subsequently, the appropriate biotinylated goat polyclonal secondary antibody was added and incubated at room temperature for $60 \mathrm{~min}$. The slides were then washed with PBST three times, incubated in diaminobenzidine 

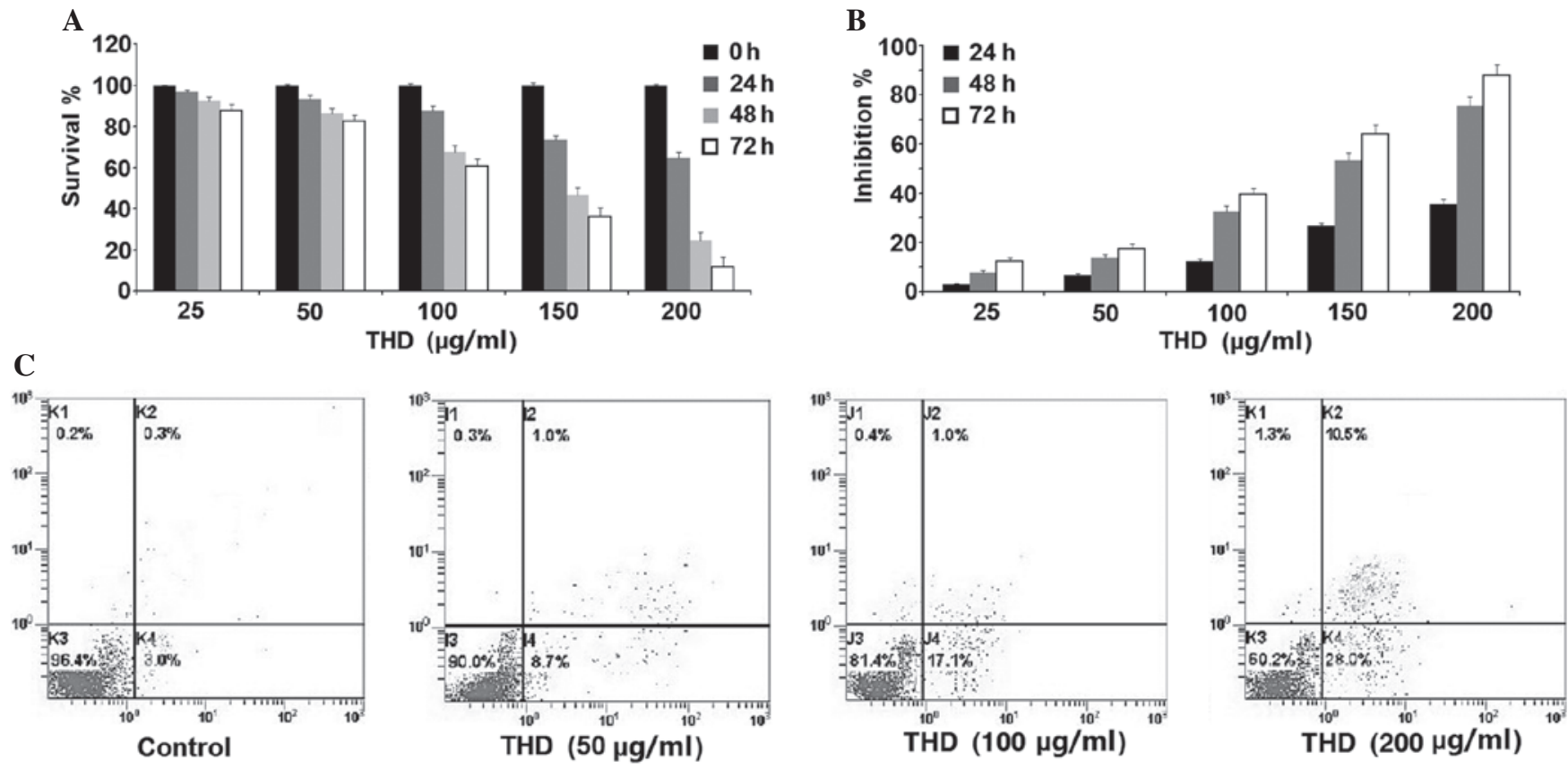

D
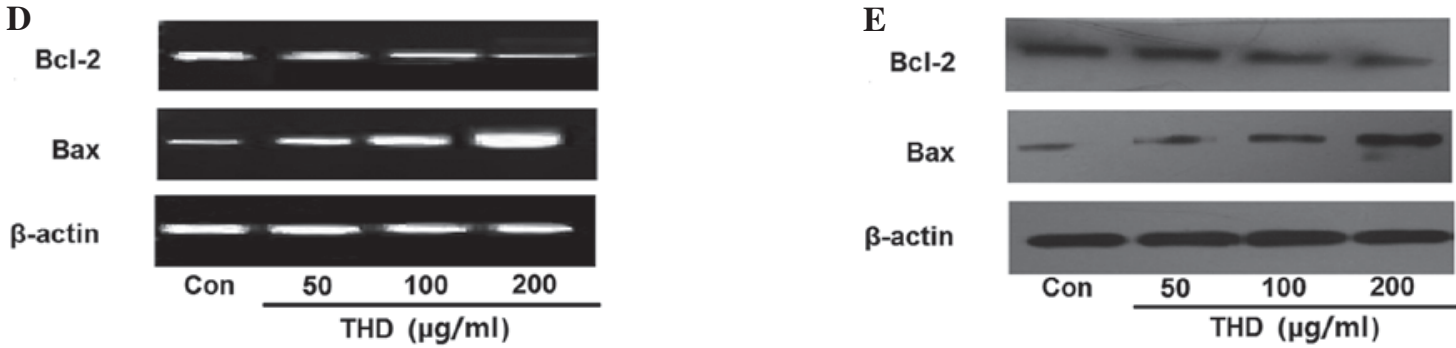

Figure 1. The inhibitory effect of THD on the growth of the pancreatic cancer SW-1990 cell line in vitro. (A) The SW-1990 cells were incubated with increasing concentrations of THD, ranging between 0 and $200 \mu \mathrm{g} / \mathrm{ml}$, for $0,24,48$ and $72 \mathrm{~h}$. The cell counting kit 8 assay was then used to analyze the cell viability. (B) The growth inhibition exerted on SW-1990 cells by the treatments was calculated and the data are presented as the mean \pm standard error. (C) The percentage of apoptotic and necrotic SW-1990 cells was analyzed using an Annexin V/propidium iodide assay. (D) Subsequent to treatment with the indicated concentrations of THD, the SW-1990 cells were harvested and the mRNA levels of Bcl-2 and Bax were analyzed by reverse transcription-polymerase chain reaction. (E) The expression of the Bcl-2 and Bax proteins in the SW-1990 cells was determined by western blotting. THD. thalidomide; Bcl-2, B-cell lymphoma 2; Bax, Bcl-2-associated X protein; Con, control.

solution for $10 \mathrm{~min}$ and counterstained with hematoxylin for $1 \mathrm{~min}$. Finally, the images were captured using a light microscope (magnification, x200; Olympus CKX41-A32RC; Olympus, Tokyo, Japan). Immunohistochemical analysis of CD34 was used to calculate the microvessel density (MVD) of the tumor xenograft.

Statistical analysis. The data were expressed as the mean \pm standard error and analyzed using SPSS software, version 18.0 (SPSS Inc., Chicago, IL, USA). Statistical analysis was performed using one-way analysis of variance (ANOVA), and the Student-Newman-Keuls test was performed as a post-hoc test subsequent to ANOVA. The Kruskal-Wallis test was used to evaluate the differences of categorical values followed by the Mann-Whitney $U$ test, which was performed as a post-hoc test. $\mathrm{P}<0.05$ was considered to indicate a statistically significant difference.

\section{Results}

Effect of THD on the growth of SW-1990 cells. The SW-1990 cells were treated with various concentrations
$(0-200 \mu \mathrm{g} / \mathrm{ml})$ of THD for $24 \mathrm{~h}, 48 \mathrm{~h}$ and $72 \mathrm{~h}$. The survival and growth inhibition rates of SW-1990 cells were determined using the CCK-8 kit assay. It was found that the proliferation and survival of the cells was inhibited in a dose- and time-dependent manner (Fig. 1A and B). SW-1990 cell death was measured using an Annexin V/PI assay. The levels of apoptosis and necrosis in the cells cultured with THD for $48 \mathrm{~h}$ were found to be increased in a dose-dependent manner compared with the control group (Fig. 1C; Table I). In addition, $48 \mathrm{~h}$ after THD incubation, RT-PCR and western blot analysis revealed that the expression of Bcl-2 was downregulated, while the expression of Bax was upregulated (Fig. 1D and E).

Effect of THD and GEM combined treatment on the growth of SW-1990 cells. The SW-1990 cells were treated with THD, GEM or a combination of the two. Firstly, the CCK-8 assay revealed that THD and GEM were each able to inhibit the proliferation and survival of SW-1990 cells. Furthermore, combined inhibition of THD and GEM demonstrated a marked increase in the suppression of cell proliferation compared with the inhibition demonstrated by THD or GEM alone (Fig. 2A and B). In addition, the Annexin V/PI assay 
A

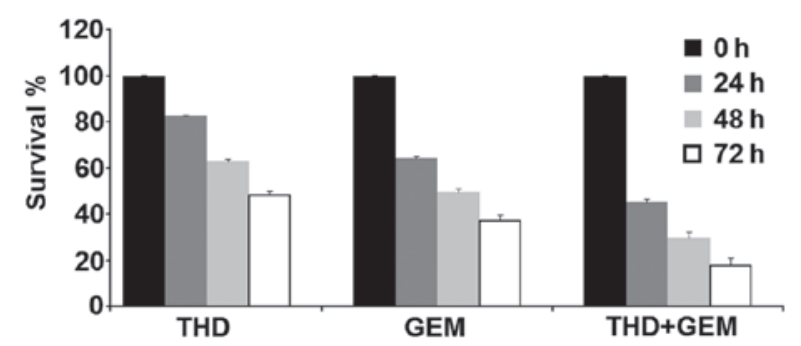

C

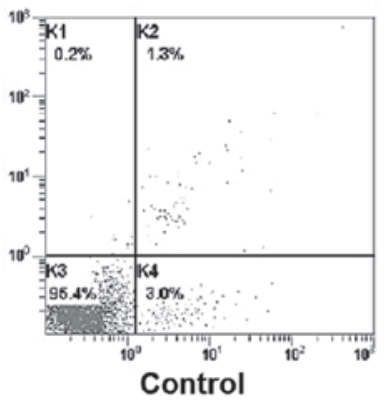

D

Bcl-2

Bax

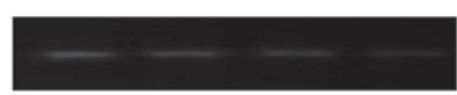

$\beta$-actin

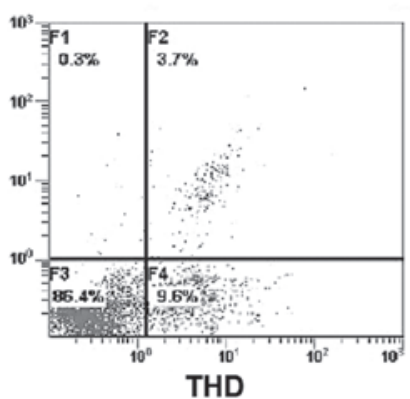

THD
B

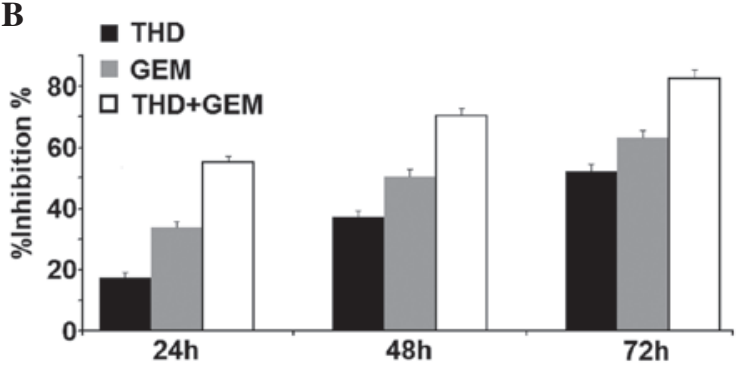

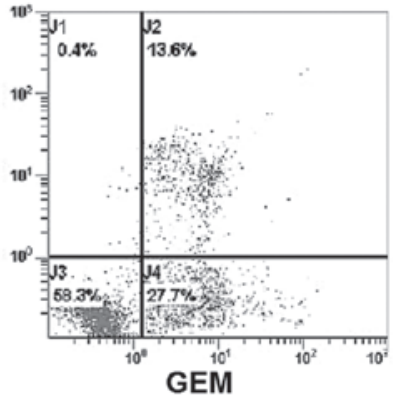

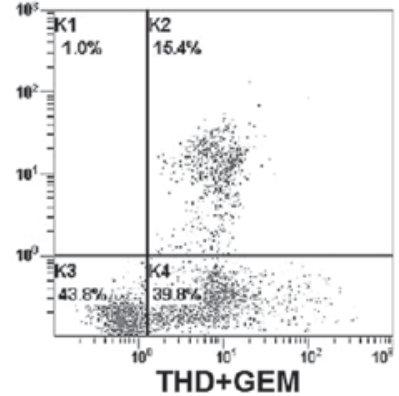

E

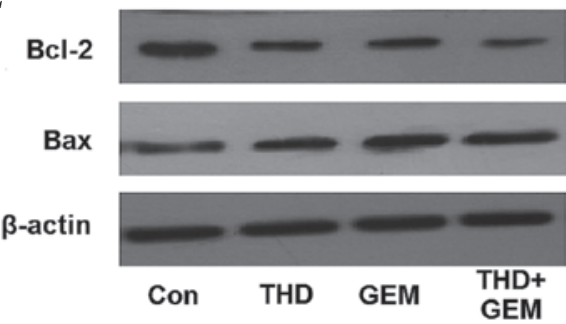

Figure 2. Inhibitory effect of THD combined with GEM on the growth of the pancreatic cancer SW-1990 cell line in vitro. (A) The SW-1990 cells were incubated with $50 \mu \mathrm{g} / \mathrm{ml}$ THD, $20 \mu \mathrm{mol} / 1$ GEM or a combination of the two for $0,24,48$ and $72 \mathrm{~h}$. A counting cell kit 8 assay was then used to analyze the viability of the cells. (B) The growth inhibition exerted on SW-1990 cells was calculated and the data are presented as the mean \pm standard error. (C) The percentage of apoptotic and necrotic SW-1990 cells was analyzed using an Annexin V/propidium iodide assay. (D) Subsequent to treatment with the indicated concentrations of $50 \mu \mathrm{g} / \mathrm{ml} \mathrm{THD}, 20 \mu \mathrm{mol} / 1$ GEM or a combination of the two, the SW-1990 cells were harvested and the levels of Bcl-2 and Bax mRNA were analyzed by reverse transcription-polymerase chain reaction. (E) The expression of the Bcl-2 and Bax proteins in the SW-1990 cells was determined by western blotting. THD, thalidomide; GEM, gemcitabine; Bcl-2, B-cell lymphoma 2; Bax, Bcl-2-associated X protein; Con, control.

detected an increased number of apoptotic and necrotic cells in the THD- or GEM-treated groups compared with the control group, and treatment with a combination of THD and GEM demonstrated an increased ability to promote apoptosis and necrosis compared with the administration of either of the two drugs alone (Fig. 2C; Table II). In addition, although the mRNA and protein expression of $\mathrm{Bcl}-2$ were each downregulated in the cells treated with THD or GEM alone, a significantly greater decrease of Bcl-2 expression was observed in the cells treated with combined treatment. Additionally, it was found that the level of Bax expression was significantly upregulated in the combined treatment group compared with the groups treated with THD or GEM alone (Fig. 2D and E).

Effect of THD on the growth of tumor xenograft in nude mice. All nude mice survived for the duration of the treatment, and the doses of THD and GEM administered resulted in no detectable toxic side-effects on the nude mice, including changes in body weight. The volumes and weights of tumor tissue were measured subsequent to the mice being sacrificed. Compared with the NS-treated control, the tumor xenograft treated with THD, GEM or combined treatment was significantly decreased in size. In addition, there was a significant decrease in the tumor volume and weight in the combined treatment group throughout the whole observation period, compared with the other groups (Fig. 3A-C). The change in Bcl-2 and Bax expression was similar to the results of the in vitro study. The combined treatment group, in particular, demonstrated a significant difference in the expression of Bcl-2 and Bax compared with the other groups (Fig. 3D and E). Additionally, the level of VEGF mRNA and protein was downregulated, in addition to the reduction in the MVD in the tumor tissues (Fig. 4).

\section{Discussion}

Previous studies have reported that THD is able to inhibit the growth of several cancer cell lines and xenograft tumors $(17,18)$. However, the precise anti-tumor mechanism of THD is not fully understood. At present, a number of studies have demonstrated that the main source of the therapeutic effect of THD on tumors is associated with the following two properties of THD. THD is able to not only suppress the proliferation and migration of tumor cells, but also induces an increase in the number of apoptotic and necrotic cells. In addition, THD may possess anti-angiogenic function that allows for the inhibition of vascular formation and growth of tumor 
Table I. Effect of thalidomide on viability of SW-1990 cells in vitro (Annexin V/PI assay).

Thalidomide concentration, $\mu \mathrm{g} / \mathrm{ml}$

\begin{tabular}{lcccc}
\cline { 2 - 4 } Form of cell death & 0 & 50 & 100 & 200 \\
\hline Apoptosis & $2.57 \pm 0.73$ & $8.77 \pm 1.30^{\mathrm{a}}$ & $18.53 \pm 1.95^{\mathrm{a}}$ & $29.43 \pm 3.75^{\mathrm{a}}$ \\
Necrosis & $0.36 \pm 0.29$ & $1.05 \pm 0.46$ & $1.70 \pm 0.73^{\mathrm{a}}$ & $13.04 \pm 1.52^{\mathrm{a}}$
\end{tabular}

Data were shown as mean $\pm \mathrm{SE}$. ${ }^{\mathrm{P}}<<0.05$, NS-treated control cells.

A

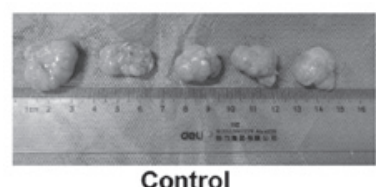

B

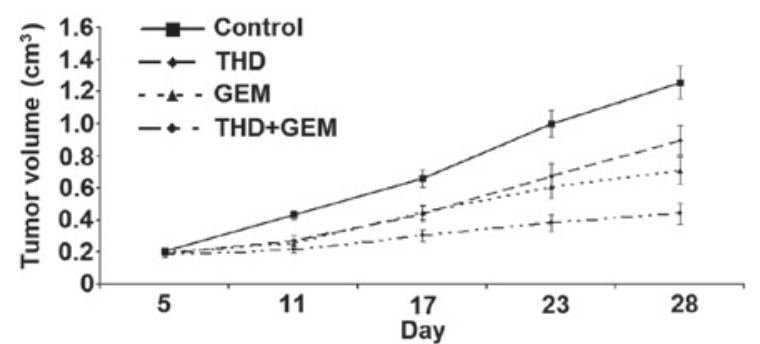

D
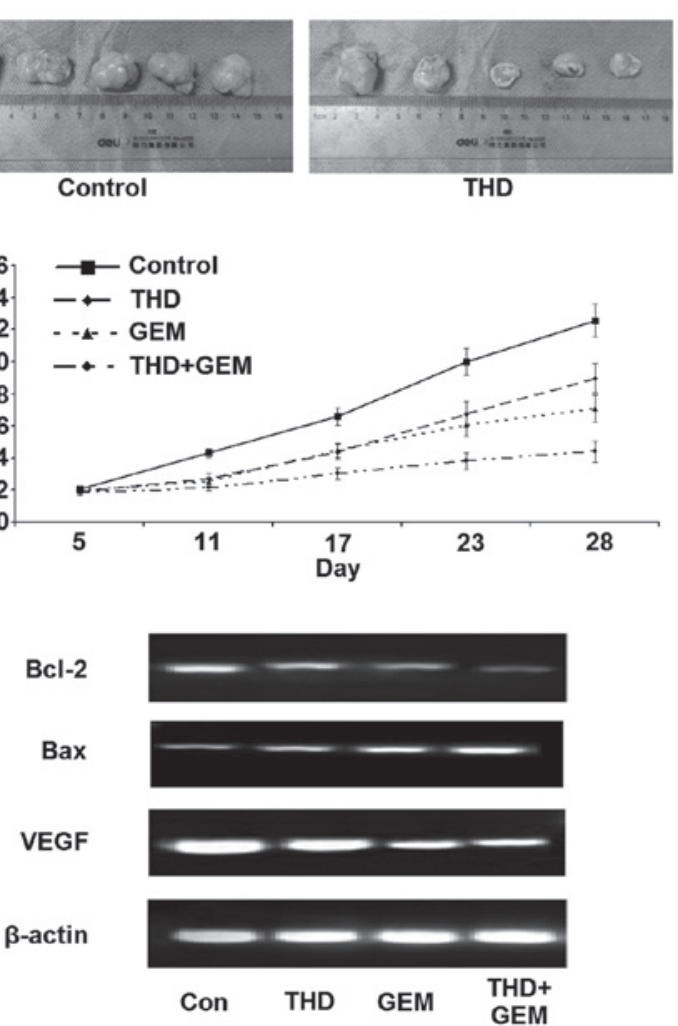

THD
C
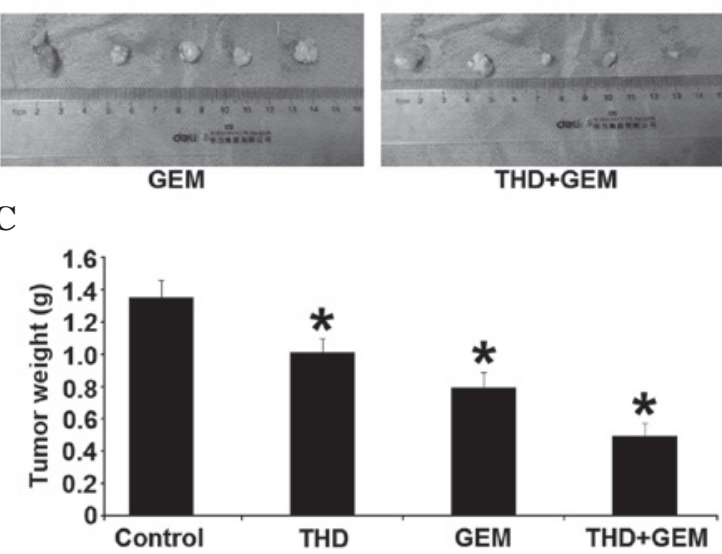

$\mathbf{E}$

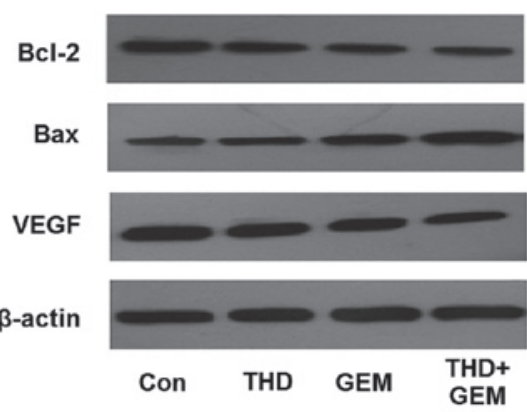

Figure 3. Inhibitory effect of combined treatment with THD and GEM on the growth of the pancreatic cancer SW-1990 cell line in vivo. (A) Gross morphology of xenografts in nude mice on the 28th day of treatment. (B) Changes in the volume of the xenograft in nude mice subsequent to treatment with THD and GEM. Compared with the NS-treated control, treatment with THD, GEM and a combination of the two demonstrated a significantly increased inhibition of tumor growth. (C) Four weeks after treatment with THD, GEM and the combination of the two, the tumor weights were evidently decreased compared with the NS-treated control treatment. The data are expressed as the mean \pm standard error. (D) Subsequent to treatment with the indicated concentrations of $200 \mathrm{mg} / \mathrm{kg}$ THD, $50 \mathrm{mg} / \mathrm{kg}$ gemcitabine and combined treatment, the mRNA levels of Bcl-2, Bax and VEGF in nude mice xenografts were analyzed by reverse transcription-polymerase chain reaction. (E) The expression of the Bcl-2, Bax and VEGF proteins in nude mice xenografts was determined by western blotting. "P<0.05 vs. NS-treated mice. THD. thalidomide; GEM, gemcitabine; Bcl-2, B-cell lymphoma 2; Bax, Bcl-2-associated X protein; VEGF, vascular endothelial growth factor.

tissues $(19,20)$. The present study aimed to examine the effect of THD on the apoptosis and necrosis of the pancreatic carcinoma SW-1990 cell line, in addition to the anti-angiogenic effect exerted on a tumor xenograft in a nude mouse model. According to the results of the experiment, the mechanism behind the THD-mediated induction of apoptosis and necrosis in tumor cells may be associated with changes in the expression of Bcl-2 and Bax. Additionally, THD may block the neovascularization process in tumor xenograft tumors through a decrease in the expression of VEGF mRNA and protein, in addition to reducing the MVD.

Several studies have suggested that pro-apoptosis proteins play a major role in tumor formation and treatment response (21).
The members of the Bcl-2 family, including Bcl-2 and Bax, are important regulators of apoptosis and anti-apoptotic processes. Bcl-2 protects against cell death and possesses anti-apoptotic characteristics. By contrast, Bax demonstrates the opposite effect and promotes cell death. Therefore, the Bax/Bcl-2 ratio is crucial to the apoptosis signaling pathway (22). In the present study, THD has been revealed to induce apoptosis and necrosis in SW-1990 cells through a decrease in the level of Bcl-2. However, the associated signaling pathways of necrosis require additional elucidation. Notably, Sung et al found that the upregulation of Bcl-2 was inversely correlated with necrosis in pancreatic acinar cells in experimental pancreatitis (23). Also, $\mathrm{Bcl}-2$ has been reported to demonstrate anti-necrotic functions 
Table II. Effect of thalidomide combined with gemcitabine on the viability of SW1990 cells in vitro.

Treatment group

\begin{tabular}{lcccr} 
Form of cell death & Control & $50 \mu \mathrm{g} / \mathrm{ml}$ thalidomide & $20 \mu \mathrm{mol} / 1$ gemcitabine & $\begin{array}{r}50 \mu \mathrm{g} / \mathrm{ml} \text { thalidom } \\
+20 \mu \mathrm{mol} / / \mathrm{lgemcit}\end{array}$ \\
\hline Apoptosis & $2.75 \pm 1.32$ & $10.88 \pm 2.97^{\mathrm{a}}$ & $29.79 \pm 4.10^{\mathrm{a}}$ & $40.02 \pm 4.65^{\mathrm{a}}$ \\
Necrosis & $1.44 \pm 0.74$ & $2.51 \pm 1.32^{\mathrm{a}}$ & $15.98 \pm 3.21^{\mathrm{a}}$ & $17.69 \pm 3.37^{\mathrm{a}}$
\end{tabular}

Data are expressed as the mean \pm standard error. ${ }^{\text {a }}<0.05$ vs. normal saline-treated control cells.

A

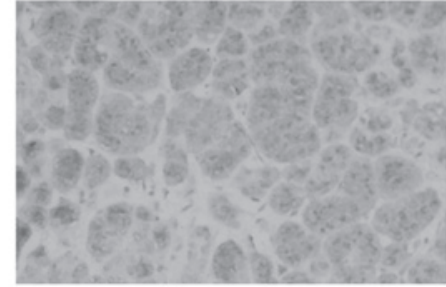

Control

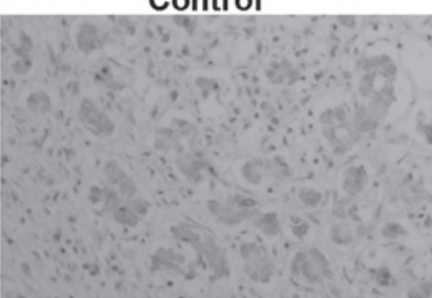

GEM

B

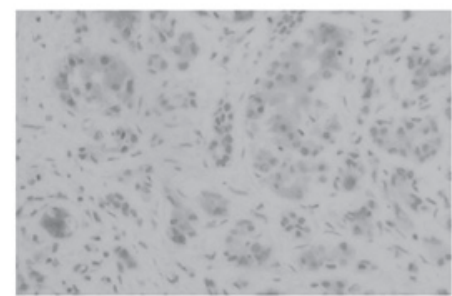

Control

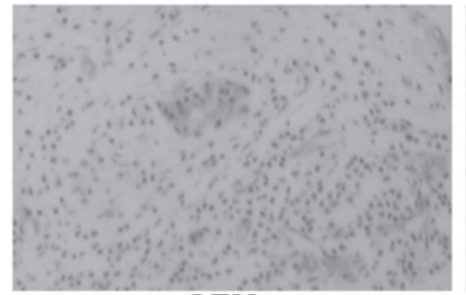

GEM

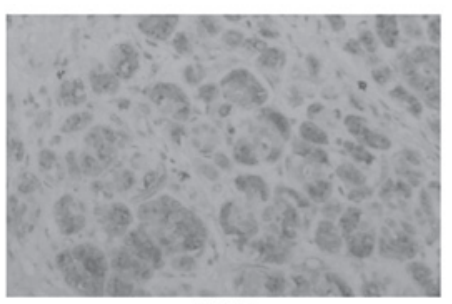

THD

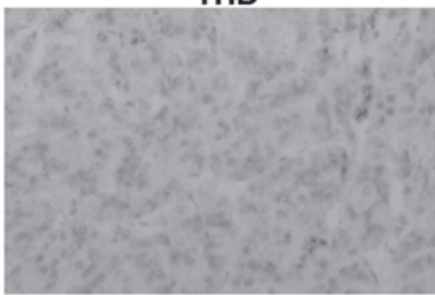

THD+GEM

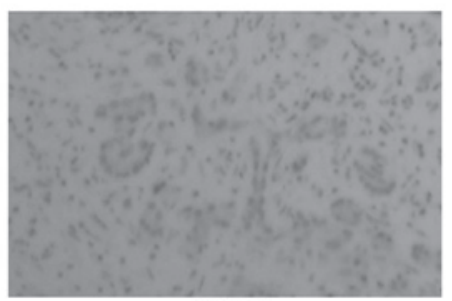

THD

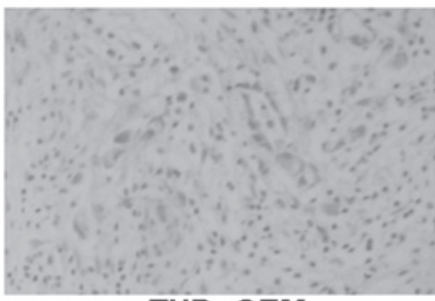

THD+GEM

Figure 4. Antiangiogenic effect of the administration of $200 \mathrm{mg} / \mathrm{kg}$ THD combined with $50 \mathrm{mg} / \mathrm{kg}$ GEM on a nude mouse xenograft model, evaluated by immunohistochemical analysis. (A) Immunohistochemical expression of vascular endothelial growth factor in paraffin sections that were probed and stained with the appropriate antibody and analyzed under light microscopy. Magnification, x200. (B) Immunohistochemical detection of the expression of cluster of differentiation 34. Magnification, x200. THD, thalidomide; GEM, gemcitabine.

in other cell types. Barbu et al revealed that the increased expression of Bcl-2 is able to prevent cytokine-induced apoptosis and necrosis of $\beta$-cells in the pancreas by counteracting mitochondrial permeability transition (24). These achievements indicated that Bcl-2 may be an important factor in the process of necrosis in cells and tissues. Additionally, the present findings are similar to the aforementioned results and suggest that the pro-necrotic effect of THD may be another mechanism for the inhibition of the growth of pancreatic cancer cells, in addition to the induction of apoptosis.

Angiogenesis is essential to the growth of any solid tumor. Antiangiogenic therapy can inhibit tumor progression indirectly through the suppressive functions of vascular formation, and result in tumor necrosis and shrinkage. THD was considered to be an angiogenesis inhibitor and used in the treatment of multiple myeloma in 1999. Subsequently, numerous studies 
demonstrated that THD possessed the ability to downregulate the VEGF concentration in several types of cancer $(6,25)$. VEGF is one of the most important indicators of tumor angiogenesis and may become a major target in the treatment strategy for pancreatic cancer. MVD is another important regulator of tumor angiogenesis in histological specimens and tumor models. Certain studies hypothesize that MVD may be an independent parameter for identifying the response to antiangiogenic treatment and is inversely associated with cancer survival $(26,27)$. The results of the present study, which revealed significantly lower VEGF expression and MVD in the carcinoma xenograft tumors treated with THD, support these aforementioned theories.

Only $14-20 \%$ of all patients with pancreatic cancer can be treated with radical surgical intervention at the time of diagnosis. Therefore, chemotherapy is important for the treatment of advanced cancer. GEM, a cytotoxic nucleoside analog, is the most commonly used antitumor drug for pancreatic cancer (3). Nevertheless, a previous study has revealed that the curative efficacy of GEM monotherapy is poor, resulting in the overall response rate of 5.0-11.0\% and the median survival duration of 5.7-6.3 months (28). In order to improve therapeutic efficacy of unresectable pancreatic cancer, numerous clinical studies have investigated GEM-based combination regimens, but the outcomes are poor. A variety of randomized phase III trials have revealed that combination therapies, including the administration of gemcitabine with other agents, such as cisplatin, capecitabine or exatecan, failed to demonstrate any improvement at a statistically significant level (29-31). Furthermore, certain authors have indicated that combination treatments may be more toxic and less well tolerated compared with the administration of GEM alone (32). As demonstrated in the present study, THD and GEM each exert an antitumor effect on pancreatic cancer cells in vitro and in vivo. In addition, the inhibitive effect is dramatically increased subsequent to a four-week treatment with GEM and THD compared with monotherapy. Considering that there is no marked difference between the body weights of nude mice in the NS-treated, THD-treated, GEM-treated and combination treatment groups, the dose applied demonstrated no detectable toxic side-effects in the mice. Thus, THD may be used in the treatment of advanced pancreatic cancer as an adjuvant agent.

In summary, THD was able inhibit the growth of pancreatic cancer and was associated with the induction of tumor cell apoptosis and necrosis, as well as inhibition of tumor angiogenesis. By contrast, combined administration of THD and GEM demonstrated significantly greater therapeutic efficacy that treatment with each of the agents alone. These findings may provide an alternative therapeutic option for the treatment of pancreatic cancer.

\section{Acknowledgements}

The present study was supported by a grant from the National Natural Science Foundation of China (No. 81300357).

\section{References}

1. Jemal A, Siegel R, Xu J and Ward E: Cancer statistics, 2010. CA Cancer J Clin 60: 277-300, 2010.
2. Ferrone CR, Brennan MF, Gonen M, et al: Pancreatic adenocarcinoma: The actual 5-year survivors. J Gastrointest Surg 12: 701-706, 2008.

3. Burris HA III, Moore MJ, Andersen J, et al: Improvements in survival and clinical benefit with gemcitabine as first-line therapy for patients with advanced pancreas cancer: A randomized trial. J Clin Oncol 15: 2403-2413, 1997.

4. Hagmann W, Jesnowski R and Löhr JM: Interdependence of gemcitabine treatment, transporter expression, and resistance in human pancreatic carcinoma cells. Neoplasia 12: 740-747, 2010.

5. McBride WG: Thalidomide embryopathy. Teratology 16: 79-82, 1977.

6. D'Amato RJ, Loughnan MS, Flynn E and Folkman J: Thalidomide is an inhibitor of angiogenesis. Proc Natl Acad Sci USA 91: 4082-4085, 1994.

7. Singhal S, Mehta J, Desikan R, et al: Antitumor activity of thalidomide in refractory multiple myeloma. N Engl J Med 341: 1565-1571, 1999.

8. Rezvani H, Haghighi S, Ghadyani M and Attarian H: Efficacy of taxotere, thalidomide, and prednisolone in patients with hormone-resistant metastatic prostate cancer. Urol J 9: 673-677, 2012.

9. Lv J, Liu N, Liu KW, et al: A Randomised Controlled Phase II Trial of the Combination of XELOX with Thalidomide for the First-line Treatment of Metastatic Colorectal Cancer. Cancer Biol Med 9: 111-114, 2012.

10. Lee SM and Hackshaw A: A potential new enriching trial design for selecting non-small-cell lung cancer patients with no predictive biomarker for trials based on both histology and early tumor response: Further analysis of a thalidomide trial. Cancer Med 2: 360-366, 2013.

11. de Souza CM, Araújo e Silva AC, de Jesus Ferraciolli C, et al: Combination therapy with carboplatin and thalidomide suppresses tumor growth and metastasis in 4T1 murine breast cancer model. Biomed Pharmacother 68: 51-57, 2014

12. Tunio MA, Hashmi A, Qayyum A, Naimatullah N and Masood R: Low-dose thalidomide in patients with metastatic renal cell carcinoma. J Pak Med Assoc 62: 876-879, 2012.

13. Dmoszynska A, Podhorecka M, Manko J, et al: The influence of thalidomide therapy on cytokine secretion, immunophenotype, BCL-2 expression and microvessel density in patients with resistant or relapsed multiple myeloma. Neoplasma 52: 175-181, 2005.

14. Marriott JB, Clarke IA, Czajka A, et al: A novel subclass of thalidomide analogue with anti-solid tumor activity in which caspase-dependent apoptosis is associated with altered expression of bcl-2 family proteins. Cancer Res 63: 593-599, 2003.

15. Georgakoudi I, Solban N, Novak J, et al: In vivo flow cytometry: a new method for enumerating circulation cancer cells. Cancer Res 64:5044-5047, 2004.

16. Forni M: Laboratory animals science: a resource to improve the quality of science. Vet Res Commun. 31 Suppl 1: 43-47, 2007.

17. Yabu T, Tomimoto H, Taguchi Y, et al: Thalidomide-induced antiangiogenic action is mediated by ceramide through depletion of VEGF receptors, and is antagonized by sphingosine-1-phosphate. Blood 106: 125-134, 2005.

18. Zhang ZL, Liu ZS and Sun Q: Effects of thalidomide on angiogenesis and tumor growth and metastasis of human hepatocellular carcinoma in nude mice. World J Gastroenterol 11: 216-220, 2005.

19. Steins MB, Padró T, Bieker R, et al: Efficacy and safety of thalidomide in patients with acute myeloid leukemia. Blood 99: 834-839, 2002.

20. Liu WM, Strauss SJ, Chaplin T, et al: s-thalidomide has a greater effect on apoptosis than angiogenesis in a multiple myeloma cell line. Hematol J 5: 247-254, 2004.

21. Estaquier J, Vallette F, Vayssiere JL and Mignotte B: The mitochondrial pathways of apoptosis. Adv Exp Med Biol 942: 157-183, 2012.

22. Shen J, Wan R, Hu G, et al: miR-15b and miR-16 induce the apoptosis of rat activated pancreatic stellate cells by targeting Bcl-2 in vitro. Pancreatology 12: 91-99, 2012.

23. Sung KF, Odinokova IV, Mareninova OA, et al: Prosurvival Bcl-2 proteins stabilize pancreatic mitochondria and protect against necrosis in experimental pancreatitis. Exp Cell Res 315: 1975-1989, 2009.

24. Barbu A, Welsh N and Saldeen J: Cytokine-induced apoptosis and necrosis are preceded by disruption of the mitochondrial membrane potential (Deltapsi(m)) in pancreatic RINm5F cells: Prevention by Bcl-2. Mol Cell Endocrinol 190: 75-82, 2002. 
25. Aydoğan S, Celiker U, Türkçüoğlu P, Ilhan N and Akpolat N: The effect of thalidomide on vascular endothelial growth factor and tumor necrosis factor-alpha levels in retinal ischemia/reperfusion injury. Graefes Arch Clin Exp Ophthalmol 246: 363-368, 2008.

26. Coultas L, Chawengsaksophak K and Rossant J: Endothelial cells and VEGF in vascular development. Nature 438: 937-945, 2005.

27. Giatromanolaki A, Koukourakis MI, Stathopoulos GP, et al: Angiogenic interactions of vascular endothelial growth factor, of thymidine phosphorylase, and of $\mathrm{p} 53$ protein expression in locally advanced gastric cancer. Oncol Res 12: 33-41, 2000.

28. $\mathrm{Xu} \mathrm{C}, \mathrm{Wu} \mathrm{A}, \mathrm{Zhu} \mathrm{H}$, et al: Melatonin is involved in the apoptosis and necrosis of pancreatic cancer cell line SW-1990 via modulating of Bcl-2/Bax balance. Biomed Pharmacother 67: 133-139, 2013.

29. Colucci G, Labianca R, Di Costanzo F, et al; Gruppo Oncologico Italia Meridionale (GOIM); Gruppo Italiano per lo Studio dei Carcinomi dell'Apparato Digerente (GISCAD); Gruppo Oncologico Italiano di Ricerca Clinica (GOIRC): Randomized phase III trial of gemcitabine plus cisplatin compared with single-agent gemcitabine as first-line treatment of patients with advanced pancreatic cancer: The GIP-1 study. J Clin Oncol 28: 1645-1651, 2010.
30. Herrmann R, Bodoky G, Ruhstaller T, et al; Swiss Group for Clinical Cancer Research; Central European Cooperative Oncology Group: Gemcitabine plus capecitabine compared with gemcitabine alone in advanced pancreatic cancer: A randomized, multicenter, phase III trial of the Swiss Group for Clinical Cancer Research and the Central European Cooperative Oncology Group. J Clin Oncol 25: 2212-2217, 2007.

31. Abou-Alfa GK, Letourneau R, Harker G, et al: Randomized phase III study of exatecan and gemcitabine compared with gemcitabine alone in untreated advanced pancreatic cancer. J Clin Oncol 24: 4441-4447, 2006.

32. Chauffert B, Mornex F, Bonnetain F, et al: Phase III trial comparing intensive induction chemoradiotherapy $60 \mathrm{~Gy}$, infusional 5-FU and intermittent cisplatin) followed by maintenance gemcitabine with gemcitabine alone for locally advanced unresectable pancreatic cancer. Definitive results of the 2000-01 FFCD/SFRO study. Ann Oncol 19: 1592-1599, 2008. 